\title{
ENTRE IDAS E VINDAS: VICISSITUDES DO MÉTODO CASTILHO NO BRASIL DO SÉCULO XIX
}

DOI: http://dx.doi.org/10.1590/2236-3459/70697

\author{
Carlota Boto'
}

'Universidade de São Paulo (USP), São Paulo/SP, Brasil

\author{
Suzana Lopes de Albuquerque" \\ "Instituto Federal de Educação, Ciência e Tecnologia de Goiás (IFG), Goiânia/GO, Brasil
}

\section{$\cos 8$}

\begin{abstract}
Resumo
As escolas de primeiras letras nas diferentes províncias brasileiras, ao longo do século XIX, tinham seus fazeres influenciados por métodos de ensino internacionalmente postos no território das ideias pedagógicas da Modernidade. Uma ação pontual foi a vinda do poeta e educador português António Feliciano de Castilho (1800-1875) para apresentação de seu método na Corte brasileira. O curso dado por Castilho passou por momentos de rejeição explícita, implicando inclusive o cancelamento do mesmo curso; o que suscita diversos questionamentos: Quais motivos levaram à rejeição do método de Castilho e o cancelamento de seu curso na Corte brasileira? Quais as perspectivas pedagógicas e quem é o professor que, ao defender o método Jacotot, estabeleceu diversos debates com Castilho?

Palavras-chave: instrução pública, Castilho, história da leitura, escola primária, educação pública.
\end{abstract}

\section{ENTRE IDAS Y VENIDAS: VICISITUDES DEL MÉTODO CASTILHO EN BRASIL DEL SIGLO XIX}

\section{Resumen}

Las escuelas primarias en las diversas provincias brasileñas, a lo largo del siglo XIX, tenían sus hechos influenciados por los métodos de enseñanza internacionalmente puestos en el territorio de las ideas pedagógicas de la Modernidad. Una acción puntual fue la llegada del poeta portugués y educador Antônio Feliciano de Castilho (1800-1875) para la presentación de su método en la Corte de Brasil. El curso impartido por Castilho pasó por momentos de rechazo explícito, implicando incluso la cancelación de su curso; lo que suscita varias preguntas: ¿Qué razones llevaron al rechazo del método de Castilho y la cancelación de su curso en la Corte de Brasil? ¿Cuáles son sus perspectivas de educación? ¿Quién es el profesor que, por defender el método Jacotot, estableció varias discusiones con Castilho?

Palabras clave: instrucción pública, Castilho, historia de la lectura, escuela primaria, educación pública. 


\title{
BETWEEN COMINGS AND GOINGS: VICISSITUDES OF THE CASTILHO METHOD IN NINETEENTH CENTURY BRAZIL
}

\begin{abstract}
The primary schools among the different brazilian provinces, throughout the XIX century, had their duties influenced by teaching methods that were internationally put on the territory of the pedagogical ideas of the Modernity. One punctual action was the arrival of the Portuguese poet and educator Antônio Feliciano de Castilho (1800-1875) for the presentation of his method to the Brazilian Court. The course lectured by Castilho faced moments of explicit rejection, even causing the cancellation of his course; something that raises several questions: which motives caused the rejection of Castilho's method and the cancellation of his course on the Brazilian Court? What are his pedagogical perspectives? Who is the professor that, by defending the Jacotot method, established several debates with Castilho?

Keywords: public instruction, Castilho, reading history, primary school, public education.
\end{abstract}

\section{ENTRE ALLÉES ET VENUES: VICISSITUDES DE LA MÉTHODE CASTILHO AU BRÉSIL DU SIĖCLE XIX}

\begin{abstract}
Résumé
Les écoles primaires dans les différentes provinces brésiliennes, tout au long du XIXe siècle, avaient leurs actions influencées par les méthodes d'enseignement postes internationaux sur le territoire des idées pédagogiques de Modernity. Une action ponctuelle a été la venue du poète portugais et éducateur Antônio Feliciano de Castilho (1800 à 1875) pour la présentation de sa méthode à la Cour brésilienne. Le cours donné par Castilho a traversé des moments de rejet explicite, ce qui implique notamment l'annulation du cours; ce qui soulève plusieurs questions: quelles raisons a causé le rejet de la méthode de Castilho et l'annulation de son cours à la Cour brésilienne? Quelles sont vos perspectives pédagogiques? Qui est l'enseignant qui, tout en défendant la méthode Jacotot, créé diverses discussions avec Castilho?

Mots-clés: instruction publique, Castilho, histoire de la lecture, école élémentaire, l'éducation publique.
\end{abstract}




\section{Introdução}

s escolas de primeiras letras em diferentes províncias brasileiras, ao longo
do século XIX, em seu cotidiano, tinham seus fazeres, em alguma medida,
influenciado por materiais e métodos de ensino baseados na circulação de modelos internacionalmente postos no território das ideias pedagógicas da Modernidade. A necessidade de se adotar um método de ensino impôs o debate entre os modos de ensino individual, simultâneo e mútuo. Havia uma efervescência de métodos pedagógicos que circulavam em outros países. A escola primária do Império brasileiro era, por sua vez, criticada por suas carências e incompletudes, sendo culpada, muitas vezes, pelas más condições físicas que apresentava; e, sobretudo, pela dificuldade de atingir o processo de formação da maioria da população. As escolas que existiam eram insuficientes para abarcar a maioria da população em idade escolar. Além disso, embora houvesse alguns edifícios construídos como escolas públicas na capital do Império, embora houvesse uma malha privada de ensino, a maior parte das escolas tinha uma estrutura material muito frágil. Faltavam utensílios, livros, mobiliário, além de pessoal docente qualificado e métodos apropriados.

Circulava na época uma concepção de infância e de educação escolar que ecoava os ideais do iluminismo francês e da Revolução. Tal ideário repercutiu no final do Império e mesmo no advento da república brasileira. A criança era, por um lado, vista por sua inocência; e por outro era concebida por sua brutalidade. Se não fosse educada, seus instintos animalescos prevaleceriam. Sendo educada, contribuiria para os progressos da pátria. A discussão pedagógica desse período era permeada pelos ideais liberais de construção do espírito público de formação do Estado-Nação à luz do que se supunha ser o percurso civilizatório do Ocidente.

A busca por esse derramamento de luzes sobre as crianças a partir da instrução pública no império brasileiro foi realizada por meio de reformas, legislação e ações pontuais, como o incentivo, por parte do imperador D. Pedro II para a ministração do curso do poeta e educador português António Feliciano de Castilho (1800-1875), bacharel em direito e sócio da Academia Real das Ciências de Lisboa. Pretendia o imperador que Castilho apresentasse seu método no Brasil. O curso dado por Castilho contou com a presença de representantes de diversas províncias brasileiras.

O método de ensino desenvolvido em Portugal por Castilho, dentre vários outros que circulavam nas províncias brasileiras em meados do século XIX, apresentava-se como uma proposta de escola moderna, caracterizada por sua função modeladora, racionalizadora, normativa e reguladora da cultura letrada. Seu método de ensino era visto como patrimônio geral e não privilégio, não sendo, portanto, tido "nem como virtude nem mercê, e sim como justiça e pagamento da dívida. Subtrair, sonegar, aos espíritos o seu sol, dificultá-lo, encobri-lo e mesmo vendê-lo é falsear a lei divina; é profanar a obra prima do Criador". (CASTILHO, 1880, p. 14).

António Feliciano de Castilho (1800-1875) era filho de um professor universitário de Coimbra. Ele ficou cego com seis anos de idade. Mas tinha uma boa memória e uma notável capacidade de aprender. Castilho foi um líder acadêmico em sua época. Dirigiu uma importante revista portuguesa, a Revista Universal Lisbonense. Essa era uma revista bastante lida em sua época; e Castilho ficou renomado como diretor da revista. Além do mais, havia o periódico, uma intenção pedagógica. Foi no começo dos anos 50 que Castilho 
publicou seu Método Português Castilho para aprendizagem da leitura e da escrita. Esse método foi criticado desde sua publicação por ser acusado de se tratar de um plágio do francês Lemare. As primeiras edições do Methodo Portuguez - Castilho para o ensino rápido e aprasivel do ler, escrever e bem falar datam de 1850, 1853, 1857 e 1908 (BOTO, 2016). O método de Castilho foi apresentado ao público em Portugal como uma tentativa de abolir o mal-estar entre professores e alunos no processo de ensino. As atividades de leitura eram seguidas de perto pela técnica da mnemônica, de modo que os alunos recordem das palavras e das letras, a partir de associações delas com histórias que se contava. Além disso, o ensino era acompanhado por palmas e por cantos, de maneira a ser obter o contentamento daquele que aprende.

Castilho contrapunha-se ao que entendia ser a escola velha. Para recusar as práticas então tradicionais de ensino, ele nomeia a letra pelo som, criando assim o que chamaria de soletração moderna. A originalidade de Castilho estaria aí:

\footnotetext{
Cada letra seria associada a uma respectiva história, vindo acompanhada pela figura geradora, a qual, por sua vez, ficaria, pela mnemonização, gravada na mente do aprendiz. Cabe recordar que o método dito 'português' foi bastante criticado a seu tempo, particularmente por professores presos ao tradicional modelo de ensino, o qual Castilho passaria a designar como 'adversário'. O método inventado pelo poeta era, pelos oponentes, taxado de pueril, de dispendioso, de trabalhoso - não factível, portanto, para escolas de um único professor. Castilho, de modo recorrente, compra a polêmica, tentando persuadir os professores no reconhecimento das virtudes postas inclusive naqueles que eram, à partida os aparentes defeitos do método. (BOTO, 2012, p. 59-60).
}

Castilho queria que seu método fosse adotado como método oficial das escolas portuguesas. E desenvolve o mesmo desejo em relação ao Brasil. Também no Brasil, a presença do português Castilho no império para apresentação de seu método de ensino simultâneo de leitura passou por momentos de rejeição explícita, implicando inclusive o cancelamento de seu curso; o que suscita diversos questionamentos: qual foi a matriz pedagógica e a forma de apropriação do método Castilho no cenário brasileiro? Quais motivos levaram à rejeição do método de Castilho e o cancelamento de seu curso na Corte brasileira? Quais as perspectivas pedagógicas e quem é o professor que, ao defender o método Jacotot, estabeleceu diversos debates com Castilho?

\section{Polêmico António Feliciano de Castilho e sua passagem pela educação}

A revista Brasil-Portugal (1899-1914) publicou no ano de 1902 uma edição comemorativa do centenário de Castilho, contendo uma série de matérias e notas sobre a vida e obra desse intelectual português. Tratava-se de um periódico dirigido às elites, especialmente as da comunidade portuguesa do Brasil e colônias. A revista, que chegou a atingir 374 números, trabalhou temáticas diversas, como história, literatura, sociologia, etnografia, etc. Tratava-se de uma boa fonte de informação também sobre a trajetória e as características de Castilho.

Se António Feliciano não tinha os agrados da beleza física, que mesmo no homem nos atraem e prendem, tinha o encanto, a sedução do espírito - era um conversador admirável; e digo conversador, porque sabia falar e sabia ouvir. A todos escutava atentamente, com uma Cortesia e polidez fidalgas, herdadas de tempos menos democráticos que os nossos. (D’AÇA, 1900, p. 9). 
Ao descrever a vida de Castilho, a revista apontava a preocupação com o analfabetismo do povo, o que, de certa forma, o teria motivado na elaboração de um método de leitura considerado como uma obra redentora, que ele buscou implantar no campo da instrução. Tratava-se de uma época na qual a ideia de democratizar o ensino correspondia, sobretudo, a espraiá-lo pelos setores mais amplos da população. Tratava-se de estender o ensino; e isso supunha facilitar o método, de modo a que todos pudessem aprender. Foi isso que Castilho julgou fazer.

Mas, como se fosse pouco tudo isso, e se esse pródigo do ouro do espírito achasse ainda mesquinha e deficiente a parte com que contribuía para a civilização do seu tempo, dez anos pendurou a lira, como ele mesmo disse e exemplificou, para se entregar a outro trabalho, a outra missão, moda de amor, de dedicação, de altruísmo. A redenção da infância pela luz, pelo ensino amorável e prático, foi a empresa nobre e altíssima a que Castilho consagrou alma e coração, difundindo por toda a parte o seu método de leitura, levando-o pessoalmente às escolas, explicando-o ele mesmo às crianças, tornando-se, enfim, o porta-voz de uma religião nova, o evangelista de uma ideia redentora. (BRASIL-PORTUGAL, 1900, p. 1).

Pode-se dizer que a dimensão pedagógica da biografia de Castilho inscreve-se em sua atuação como divulgador de seu Método Português-Castilho para o ensino rápido e aprazível do ler, escrever e bem falar. O projeto de ensino da leitura e da escrita desenvolvido por Castilho valorizava o gosto da infância no desenvolvimento de atividades caracterizadas pela metodologia lúdica. Assim, o canto, as palmas, as marchas, tudo isso, em tese, abriria lugar para a descontração, para a espontaneidade, para o riso, para o descontrair-se: "como cantar é inteiramente do gosto da puerícia, convém que, por um canto, se abra a escola e por outro se remate; desse modo, os discípulos terão pressa em chegar, e empenho em se conservar até o fim". (CASTILHO, 1880, p. 10).

O ensino proposto pelo português António Feliciano de Castilho era inovador. O desafio será buscar a maneira como essa inovação se consubstanciou nas práticas; especialmente no modo como esse ensino foi apropriado por parte de algumas províncias brasileiras à época, em especial Goiás e Alagoas. A escolha por Goiás e Alagoas deve-se ao fato de serem os acervos documentais aos quais tivemos acesso para proceder à pesquisa. No entanto, para a reconstituição dessa circulação do método Castilho em algumas províncias do Brasil, será necessário compreender os modos pelos quais o modo de ensino simultâneo ocorria no Brasil. Castilho desdenhava dos que recusavam o ensino simultâneo e não atendiam às inovações, como suas atividades ritmadas, dotadas de nítida conotação disciplinadora, bem como a leitura escolar feita em coro e as demais atividades previstas para o grupo-classe. Castilho considerava seu método superior ao ensino mútuo, pois, segundo ele, em "um só mês de ensino rítmico nas nossas escolas dá mais fruto real, que dois anos, bem repicados e apitados de ensino mútuo". (CASTILHO, 1880, p. XLVI). A criança era vista por Castilho como um ser ativo, que deveria ser conduzida por um modelo de ensino também ativo em relação ao modo de mobilizar os saberes e os conteúdos do ensino. Nesse sentido, esse método considerava "os discípulos como filhos, pelo menos como amigos, em todo o caso como homens; não recuse jamais uma elucidação que se requeira; provoque até proporem-se-Ihe dúvidas". (CASTILHO, 1880, p. 8).

A superioridade descrita por Castilho do seu modelo de ensino simultâneo em relação ao modo de ensino mútuo partia da compreensão de que, em sala de aula, seria 
necessário regrar o heterogêneo, dar forma ao que era informe, normalizar o descontínuo, sempre sob a liderança inamovível do mestre. Protagonizando debate intenso sobre métodos de ensino, Castilho encontrou inúmeros opositores. Ele só defendia a escola que nasceu de sua pena; acreditando que ela seria a única instituição pedagógica assente exclusivamente em bases naturais.

As críticas que Castilho recebia na época de seus opositores derivavam da acusação segundo a qual se dizia ter ele transformado a escola em um território de experimentações pedagógicas, negando as tradições nacionais. Além disso, dizia-se à época que a rapidez do ensino ocasionava um rápido esquecimento por parte dos alunos. Finalmente, considerava-se que o ensino com canto, marchas, palmas e ritmo não preparava para as durezas da vida. O método de Castilho foi bastante criticado a seu tempo, particularmente por professores e educadores adeptos do tradicional modelo de ensino. Castilho designava seus opositores de "adversários". Esses adversários não estavam limitados às fronteiras portuguesas. Nas duas províncias brasileiras estudadas, localizamos embates na apropriação do método Português-Castilho. Nesses embates, observa-se uma resistência contra os princípios de uma pedagogia ativa, composta por uma escola pautada pelo modo de ensino simultâneo, com um modelo de método atraente, com abertura para o experimento, movimento, ludicidade em detrimento de uma escola com práticas tradicionais, caracterizada pela imobilidade das crianças e por práticas de correções corporais.

\section{Os embates na apropriação do Método Castilho em território brasileiro: leitura de fontes das províncias alagoana e goiana}

As escolas de primeiras letras nas diferentes províncias brasileiras adotaram materiais e métodos baseados na circulação do debate advindo de um contexto de internacionalização. A necessidade de tratar do método de alfabetização impôs o debate sobre o modo individual, o ensino simultâneo e o ensino mútuo. Observou-se uma busca pela apropriação de variados métodos de ensino presentes em outros países, o que, de certa forma, desqualificava como ultrapassados todos os métodos e técnicas de ensino que até então eram utilizados pelo Império brasileiro. Nesse sentido, buscava-se o novo para deslegitimar o que se considerava obsoleto. Procedia-se a críticas contra a escola brasileira imperial quanto às carências e incompletudes, sendo culpada por sequer oferecer, como já apontamos anteriormente, espaço físico adequado bem como mobiliário, pessoal docente qualificado e métodos adequados para a infância. A partir de agora, a proposta é analisar o método de ensino simultâneo de leitura proposto por António Feliciano de Castilho, a partir de sua apropriação no cenário brasileiro, especificamente, nas províncias goiana e alagoana, tal como já foi anteriormente justificado.

A necessidade de aprofundar as fontes para análise das matrizes do método de ensino proposto pelo português António Feliciano de Castilho e de como se deu a apropriação dessa inovação em território brasileiro, atentando para a concepção de infância daí decorrente, é desafiadora por buscar compreender as próprias matrizes do método de ensino simultâneo, bem como as formas de sua introdução no território brasileiro. António Feliciano de Castilho tornou-se referência internacional, a partir de meados dos anos cinquenta no debate sobre métodos de ensino no mundo luso-brasileiro. Os estudos de Castilho pretendiam ser um modelo para o ensino de primeiras letras no Brasil. O fato é 
que o relatório apresentado à presidência da província de Alagoas, em 1857, pelo primeiro diretor da instrução pública, Silva Titara, assinala que "trazia a novidade de se estar ensaiando em uma escola da capital o método chamado de Leitura Repentina, de José Feliciano de Castilho. Para estudá-lo no Rio de Janeiro, onde se achava o autor do método, o governo comissionou o professor José Francisco Soares, que era talvez o mais abalizado preceptor da Província”. (COSTA, 1931, p. 13).

O método simultâneo contribuiu para o processo de delimitação de um espaço próprio para o aprendizado, pela marcação de um tempo para cada lição - que passava não mais pela lição a ser dada de maneira individual, mas pela definição de um universo de saberes e pela exigência de um profissional dotado de competências para reger uma classe homogênea.

O ensino simultâneo era indicado como método apropriado para todos os conteúdos ministrados nas escolas de primeiras letras. Os documentos referentes ao cenário de formação do estado nacional brasileiro o recomendavam para a prática do magistério nas escolas da Corte, na capital do Império. De acordo com o decreto nำ1331, de Couto Ferraz, em seu artigo 73: "o método do ensino nas escolas será em geral o simultâneo. Poderá, todavia, o Inspetor Geral, ouvindo o Conselho Diretor, determinar, quando o julgue conveniente, que se adote outro em qualquer paróquia, conforme os seus recursos e necessidades".

Nesse momento, além da circulação de métodos como o de Daligault, autores brasileiros como o alagoano Joaquim José de Araújo produziram compêndios fundamentados em tais materiais que apontavam para a superioridade do método de ensino simultâneo em relação aos métodos individuais e mútuo, até então presentes nas práticas das escolas de primeiras letras. Joaquim José de Araújo escreveu o Compendio de pedagogia prática, em 1886, tendo por base o trabalho do francês Daligault.

Em ofício expedido à Instrução Pública da Província de Alagoas foi localizado o primeiro contato com o método Castilho, a partir da viagem do vice-diretor da Instrução Pública - Manuel Lourenço Silvério - em 1855, para a província da Bahia, a fim de avaliar o trabalho do professor Antonio Gentil Ibirapitanga, que já utilizava tal método.

Nos relatos do observador, o professor Antonio Gentil apresentava uma visão do método Castilho não como um mero luxo para figurar nas bibliotecas, mas satisfatório pela economia de tempo no ensino, já que transformava a fadiga dos meninos - vistos como ativos por natureza - em alegria, devido ao constante movimento do corpo e consonância do canto. O professor responsável por tal visita sugeriu a adoção do método na província alagoana e consequentemente o envio de um ou dois representantes à Corte brasileira, já que Castilho ministraria cursos sobre seu método.

Em outros ofícios, a Diretoria da Instrução Pública relata o envio à Corte de um professor de primeiras letras do $2^{\circ}$ distrito, de nome Francisco José Soares, na data de 26 de março de 1855, para estudar o método junto com o próprio Castilho, que lá se encontrava para ofertar um curso. Sua ida estava condicionada à elaboração de um parecer apresentando uma ideia geral acerca do método de ensino apresentado, para destacar os proveitos e as vantagens que dele poderia colher.

A província de Goiás também teve um representante para tal curso. Abreu (2008) registrou o momento em que o presidente da província de Goiás, Antonio Candido da Cruz Machado, enviou à Corte o professor de primeiras letras da instrução pública, Feliciano 
Primo Jardim, para aprender o referido método com o próprio Castilho e depois aplicá-lo nas escolas goianas (Relatório de 1855).

Quando o representante chegou à Corte, porém, Castilho já não se encontrava. $\mathrm{O}$ professor Feliciano P. Jardim iniciou uma série de relatos sobre suas visitas às escolas da Corte e constatou que os professores da rede pública da Corte estavam em processo de transição do método mútuo para o simultâneo. Era um período de implantação do método simultâneo. Por isso, muitas escolas por ele visitadas tinham um modo misto de ensinar; e, em todas elas, encontravam-se monitores de classe. As aulas obedeciam ao som da campainha e aos sinais dos monitores que se sentavam ao lado do professor.

Abreu (2008) aponta para a não-adoção do método Castilho nesse contexto na província goiana, apesar de constatar melhor resultado em um mesmo espaço de tempo. Abreu aponta, nesse sentido, para a conclusão do professor Feliciano P. Jardim:

Se o método Castilho não podia ser admitido na Corte, onde o próprio autor o explicou a vários professores, muito menos o seria na província de Goiás (Relatório do professor Feliciano Primo Jardim). O presidente da província concluiu que o método Castilho não poderia ser adotado em Goiás, uma vez que não havia na província professor habilitado para aplicá-lo nem rendas provinciais suficientes para adquirir todos os utensílios exigidos para a adoção dessa metodologia. (ABREU, 2006, p. 196).

Os representantes provinciais enviados à Corte divergiram em relação à adoção do método e à concepção de infância daí decorrentes. Nesse sentido, o professor alagoano encarregado de participar do curso de Castilho emitiu um ofício ${ }^{1}$ à Diretoria de Instrução Pública, em 9 de maio de 1855, informando a interrupção do curso de Castilho por rejeições de ordem político-nacionalistas. Assim, foi proposto que houvesse a reposição das 30 aulas restantes em casa de Castilho, somente para os interessados. Dos 600 alunos matriculados, somente 21 participantes continuaram a frequentar o curso na casa de Castilho, dentre eles os representantes das províncias alagoana e goiana.

É possível dizer (BOTO, 2012, p. 60) que Castilho recebia em sua época inúmeras críticas de seus opositores, muitas delas o acusando de ter transformado a escola em um local de experimentação pedagógica, outras acentuando o fato de que sua metodologia negava as tradições nacionais, e ainda outras assegurando que o método de Castilho ensinava preocupado excessivamente com um excesso de rapidez; o que ocasionaria esquecimento por parte dos alunos. Havia finalmente alguns que o criticavam por ser seu método alegre, com cantos, palmas, marchas, ritmos, enfim, que não preparavam os alunos para as durezas da vida...

No mesmo ofício, o professor Francisco José Soares - mestre e proprietário de escola primária de Maceió, Colégio São José - referiu-se às visitas à casa onde se hospedava Castilho nas terças e sextas-feiras: momentos de maior aprendizado sobre 0 método, e de melhor preparação para as aulas práticas sob a direção do professor baiano Antonio Gentil, participante do curso. A aula prática contava com a presença de 21 alunos que, segundo Soares, era sem dúvida "preferível enquanto ensino de leitura".

O parecer expedido pelo representante da província alagoana acerca do método Castilho apontou para uma melhora no sistema de ensino da leitura. Contudo, discordava

\footnotetext{
${ }^{1}$ Relatório do professor Feliciano Primo Jardim. Documento manuscrito avulso do Arquivo Histórico Estadual de Goiânia. Ano: 1858. Caixa: 123.
} 
da rapidez espantosa anunciada na aprendizagem das crianças pelos seus defensores:

Em relação ao seu parecer a respeito do proveito e vantagens, José Francisco Soares, é minha opinião que o método de Castilho não pode apresentar essa vantagem da rapidez espantosa, que se diz. Creio sim que ele pode melhorar o sistema antigo pelo processo que cria da mnemonização e da leitura auricular e o da leitura auricular alternada. O primeiro prende a atenção das crianças e pode fazer com que elas aprendam o alfabeto em muito menos tempo do que pelo sistema antigo; portanto, quanto à escrita, o sistema de Castilho melhora o antigo nos seguintes termos: que a criança que pelo sistema antigo aprendia a escrever bem e caligraficamente em três anos (suponhamos), mas sem ortografia alguma, hoje poderá aprender em mesmos três anos caligráfica e ortograficamente. É, por certo um melhoramento, não há dúvida; mas não há a rapidez espantosa. (Relatório da Diretoria de Instrução Pública de Alagoas. 26 de março de 1855).

No mesmo ofício, aparecia uma solicitação do professor de primeiras letras, referente ao pagamento dos 13 exemplares do Método Português-Castilho com os respectivos quadros adquiridos por ele no Rio de Janeiro para serem usados nas aulas; resultando na importância de 24\$000. Além desse valor, solicitou o professor a aquisição de objetos para a aplicação do método nas escolas de primeiras letras da província alagoana (Quadro 01).

Quadro 01 - Relação de objetos necessários para a aula de 1르 letras do professor Jose Francisco Soares no 2 ํㅡㄹ districto pelo método Castilho.

\begin{tabular}{|l|l|}
\hline \multicolumn{2}{|c|}{ RELAÇÃO DE OBJETOS NECESSÁRIOS PARA A AULA DE 1̊ LETRAS DO PROFESSOR } \\
\hline 1 & Um mississipe de leitura; \\
\hline 2 & Um quadro preto, para escrever com giz; \\
\hline 3 & Quarenta e quatro quadros e cujos modelos já existem anexos aos compêndios; \\
\hline 4 & $\begin{array}{l}\text { Quarenta e quatro caxilhas de madeira para se colocarem os quadros acima, a serem } \\
\text { pregados à parede d'aula; }\end{array}$ \\
\hline 5 & Um grande campanário à imitação de um pequeno que existe; \\
\hline 6 & Duas edições de traslados; \\
\hline 7 & Cinquenta ardósias; \\
\hline 8 & $\begin{array}{l}\text { Duzentos exemplares das lições do manuscrito corrigidas do Método pelo professor Gentil } \\
\text { da Bahia; }\end{array}$ \\
\hline 9 & Duzentas ditas das regras e exercícios; \\
\hline 10 & Um tinteiro para mesa do professor; \\
\hline 11 & Um armário para guardar os objetos d'aula; \\
\hline 12 & Um compassador; \\
\hline 13 & Uma pequena varinha, para apontar; \\
\hline 14 & Giz e esponja; \\
\hline 15 & Uma cadeira de braço; \\
\hline 16 & Uma mesa para substituir a que existe. \\
\hline
\end{tabular}

Fonte: Arquivo Público do Estado de Alagoas. Caixa 60. 
Tal quadro aponta para o elevado número de utensílios exigidos para a aplicação do Método de Leitura Repentina e a consequente necessidade de investimento financeiro, aspecto, que dificultava sua adoção, por exemplo, na província de Goiás.

A segunda edição da obra de Castilho, que circulou no Brasil, Método Castilho para o ensino rápido e aprazível do ler impresso, manuscrito e numeração e do escrever, datada de 1880, encontra-se disponibilizada pelo site da Universidade do Porto. Apropriada, segundo o autor, para a escola e família, e dedicada a D. Pedro II, discorria sobre a necessidade da verdade e a ciência, filha de Deus, enquanto patrimônio de todo gênero humano.

O derramamento de luzes sobre as crianças a partir da instrução era considerado para Castilho justiça e pagamento da dívida: "subtrair, sonegar, aos espíritos o seu sol, dificultar-lhe, encobrir-Ihe e mesmo vendê-lo é falsear a lei divina; é profanar a obra prima do Criador". (CASTILHO, 1880, p. 14).

Seu método baseava-se no ritmo a ser acompanhado pelos discípulos com uma palmada ou pancada de vara a cada palavra, sílaba ou letra proferida, sendo indispensável o uso do compassador - "máquina que ideei para marcar aos olhos e aos ouvidos os tempos com qualquer grau de velocidade desejável, a cadência rítmica com muito mais facilidade se adquirirá e com muito mais perfeição". (CASTILHO, 1880, p. 16). A marcha também era apresentada para marcar a decomposição da palavra em sílabas e destas em letras.

No prólogo, Castilho (1880) responde a três perguntas: qual era a história de seu método? O que é esse método? E de quem é esse método? Em relação à primeira indagação, o autor aponta para a necessidade encontrada em sua prática de ensino, na Ilha de São Miguel, em 1848, quando foi professor em escolas rurais de primeiras letras. Naquele momento, segundo ele, havia criado e iniciado seu próprio método, pelo contato com diversas cartilhas nacionais e estrangeiras, modernas ou antigas. Sobre o conceito do referido método, Castilho apontou características como a decomposição e leitura auricular, mnemonização por figuras e histórias de letras, caracteres e sinais, além da introdução do ritmo pelo surgimento do canto, das palmas e das marchas.

A leitura alternada consistia na "biforme repetição do mesmo processo" (BOTO, 2012, p. 57) a partir da composição do objeto da leitura - a palavra - para que o aluno reconhecesse seus elementos sonoros correspondentes aos valores da escuta das letras.

\footnotetext{
Compreendendo que a habilidade da leitura deriva da competência da fala, o método de Castilho, que se pretende explicitamente simples, eficaz e rápido, combina, analisa e disseca sons da palavra falada, decompondo-a em seus elementos fônicos e recompondo-a na sua totalidade de significado. É para tanto que Castilho sugere práticas entrelaçadas de decomposição das palavras em letras, atribuindo a estas a sonoridade que lhes seria original, para reconstituir, no final, a lógica da palavra inteira. (BOTO, 2012, p. 56).
}

A divisão do seu método era baseada na analogia das letras ou "simpatias mútuas". Para a introdução de cada letra, contava-se uma história baseada na figura representativa da letra. Ao término de cada lição (Quadro 02), havia um divertimento que seria uma forma lúdica de aplicar o que foi ensinado. (CASTILHO, 1880, p. 14). 
Quadro 02 - Lições do Método Castilho.

\begin{tabular}{|c|c|}
\hline \multicolumn{2}{|r|}{ LIÇÕES DO MÉTODO CASTILHO } \\
\hline Lição 1 & $\begin{array}{l}\text { Análise e síntese das palavras; distinção de seus elementos em sons e articulações; letras } \\
\text { vogais, ou sinais visíveis em que os sons se traduzem, ritmo. }\end{array}$ \\
\hline Lição 2 & Recordação da primeira. Mostram-se as consoantes que não têm análogas, m, n, I, r. \\
\hline Lição 3 & $\begin{array}{l}\text { Repetição dos exercícios. Mostram-se as consoantes que tem análogas, a saber: b e p, d e } \\
\text { t, f e v. }\end{array}$ \\
\hline Lição 4 & $\begin{array}{l}\text { Repetição das precedentes. Ajuntam-se as consoantes uníssonas, ou de idêntico valor q, k, } \\
\text { c; c, s, z e x; j e g. }\end{array}$ \\
\hline Lição 5 & Recordação dos precedentes. Sons nasalados. \\
\hline Lição 6 & Recordação dos precedentes. Articulações compostas. \\
\hline Lição 7 & Recordação dos atrasados. Leitura em palavras. \\
\hline Lição 8 & $\begin{array}{l}\text { Recordação dos atrasados. Elementos da palavra que se representam por mais de um sinal. } \\
\text { Sinais que representam a diversos valores. }\end{array}$ \\
\hline Lição 9 & Divisão das letras em vogais e consoantes. \\
\hline Lição 10 & $\begin{array}{l}\text { Recordação dos atrasados. Leitura de "logogrifos". Vencem-se as dificuldades que opõem a } \\
\text { leitura certas combinações de letras. Leitura de palavras com sucessivas subtrações de } \\
\text { letras. }\end{array}$ \\
\hline Lição 11 & Recordação. Exposição e formulação mnemônica da ordem alfabética. \\
\hline Lição 12 & Recordação. Vários alfabetos impressos, mostrados uns pelos outros. \\
\hline Lição 13 & $\begin{array}{l}\text { Recordação dos atrasados. Pontuação e diversos sinais que na escrita se empregam para } \\
\text { aclarar o sentido e determinar as inflexões. }\end{array}$ \\
\hline Lição 14 & $\begin{array}{l}\text { Recordação. Catálogo das palavras curtas mais usuais. Catálogo das terminações mais } \\
\text { frequentes em português. Contos para ler com pontuação. }\end{array}$ \\
\hline Lição 15 & Pontuação, regras, leitura auricular, leitura de manuscrito. \\
\hline Lição 16 & Abreviaturas mais notáveis. \\
\hline Lição 17 & Decomposição; leitura auricular; regras; pontuação; escrita na ardósia. \\
\hline Lição 18 & Pré-noções numéricas. \\
\hline Lição 19 & Recordação de contagem vocal. "Mnemonização" dos algarismos arábicos. \\
\hline Lição 20 & Leitura de números. \\
\hline Lição 21 & Leitura de numeração romana. \\
\hline
\end{tabular}

Fonte: Planilha sintetizada e elaborada pelas pesquisadoras a partir da obra original Metodo Castilho para 0 ensino rapido e aprasivel do ler impresso, manuscrito, e numeração e do escrever.

Apesar do investimento em treinamentos na Corte e visitas às outras províncias, houve muita resistência à adoção do método Castilho, enquanto ação de governo, em diferentes províncias brasileiras. Costa (2011, p. 41) apontou para o ceticismo com o qual fora acolhido, sendo combatido por José Alexandre Passos, professor e filólogo alagoano, autor de várias obras sobre o tema do ensino da leitura e da escrita. Os confrontos entre Passos e Castilho talvez fossem fruto da grande rejeição nacional dos representantes provinciais em relação ao método de leitura repentina. O fato é que, em decorrência da adesão de Soares às lições do intelectual português, criaram-se sérios impasses nas relações entre os professores do Liceu de Maceió e o presidente da província. Conforme 
Duarte (1961), o irmão de Passos, Ignacio Joaquim Passos, foi demitido do cargo de lente de Retórica da referida instituição para que Francisco José Soares ocupasse o cargo.

Nesse contexto observam-se as resistências ao princípio ativo e à dimensão prática da proposta de Castilho. O contexto político e nacionalista fez com que, nesse momento, não houvesse satisfação unânime acerca desse método de educação ativa baseado na experiência do ensino simultâneo.

Um aspecto importante que necessita de maior atenção diz respeito às razões pelas quais Castilho interrompeu o curso, antes tão propalado nacionalmente. Havia 600 inscrições. Várias hipóteses para tal cancelamento são apresentadas, como as questões pessoais relatadas na província alagoana, os embates políticos e nacionalistas entre os que defendiam um método brasileiro de Costa e Azevedo, ou ainda os defensores de uma forma tradicional de conceber o processo educativo contrários às concepções de Castilho sob uma nova forma de ver a criança, como um ser ativo, capaz de interagir com pares e professores.

Abelardo Duarte (1961) mencionou as dimensões desses conflitos entre os irmãos e o representante do método Castilho, noticiados inclusive no jornal Diário das Alagoas (1859), quando Ignacio Joaquim Passos e seu irmão José Alexandre Passos eram ainda redatores.

O princípio ativo da educação já se encontrava no século XVII nas formulações de Comenius, cujo propósito era o de adaptar conteúdos e materiais adequados para a idade infantil: "dessa forma, sem nenhuma dificuldade, as crianças podem se exercitar para uma vida ativa, pois sua própria natureza as estimula a agir". (COMENIUS, 2011, p. 61). Em Comenius, o amor à escola deveria ser estimulado a partir da distribuição de materiais atrativos como livros e pensas, com o objetivo de que a doce brincadeira substituísse a concepção de ensino baseada em trabalho penoso.

Apresenta-se dessa forma um impasse entre o controle da infância pelos adultos, cujo ego e individualidade deveriam ser preservados por cuidados especiais a partir do autocontrole e pensamento lógico contrastando com a concepção de infância enquanto detentora de suas próprias regras de desenvolvimento com princípio ativo de encanto e curiosidade.

Castilho desdenhava dos que recusavam o ensino simultâneo e não atendiam as inovações como atividades ritmadas dotadas de nítida conotação disciplinadora, bem como da leitura escolar feita em coro e as demais atividades previstas para um grupo-classe.

A legislação que passou a regular a escola elementar, as experiências de formação de professores, a publicação de materiais pedagógicos e diversificados métodos apontaram para um conjunto de iniciativas que visavam organizar a escola elementar. Todavia a busca de formação de uma criança nesses moldes deparava-se com as velhas práticas docentes de castigos corporais, ensino memorialístico, livros de leitura e métodos de ensino que passavam a ser compreendidos como não adequados para as crianças.

É interessante pontuar que, mesmo nesse modelo de escola que pretendia renovar os métodos tidos por ultrapassados e ineficazes, os preceitos de amor a Deus e ao próximo, a valorização das práticas de civilidade e de caridade, fossem centrais para a dimensão da formação. 


\section{Rejeição ao Método Castilho e a interrupção de seu curso na Corte brasileira}

Ao nos debruçarmos sobre as fontes referentes à instrução pública nas províncias de Goiás e Alagoas, observamos que ambas enviaram representantes ao curso de Castilho que iniciara em 22 de março de 1855.

O presidente da província de Goiás, Antonio Candido da Cruz Machado, enviou à Corte o professor de primeiras letras da instrução pública Feliciano Primo Jardim para aprender o referido método com o próprio Castilho, e depois aplicá-lo nas escolas goianas (Relatório de 1855). Quando o representante chegou à Corte, porém, Castilho já lá não se encontrava.

Em ofícios localizados no Arquivo Público de Alagoas, localizamos o envio à Corte de um professor de primeiras letras do $2^{\circ}$ Distrito, Francisco José Soares, na data de 26 de março de 1855, para o referido curso. Sua ida estava condicionada à elaboração de um parecer destacando os proveitos e as vantagens que de tal método se pudesse obter.

Os representantes provinciais enviados à Corte, assim como os respectivos presidentes, divergiram em relação à adoção do método e à concepção de infância daí decorrente. Nesse sentido, o professor alagoano encarregado de participar do curso de Castilho emitiu um ofício à Diretoria de Instrução Pública, em 9 de maio de 1855, informando a interrupção do curso de Castilho, por rejeições de ordem político-nacionalista. Tratavase, nesse sentido, de uma recusa do método de Castilho, que passava pela rejeição ao fato de ser ele um método português, que concorria, portanto, com similares no Brasil. Além disso, o fato de o método abordar o ensino simultâneo valendo-se do ritmo de palmas, marchas e cantos também fazia com que houvesse questionamentos e restrições à sua aplicação.

A hipótese apresentada a partir da literatura alagoana de Craveiro Costa refere-se à embates políticos e nacionalistas entre os que defendiam a forma tradicional de entender o processo pedagógico e os defensores da nova forma de ver e de compreender a criança, como um ser ativo, capaz de interagir com seus pares e professores. Vários são os questionamentos sobre os motivos que levaram à interrupção do curso de Castilho, que fora tão propalado nacionalmente, alcançando um conjunto de 600 inscrições. Questionase a natureza desses conflitos, os posicionamentos políticos e pedagógicos das pessoas que estavam inscritas no curso, as diferentes concepções de educação presentes durante a realização do curso e as motivações que ocasionaram seu cancelamento.

Após o ocorrido, Castilho se propôs a repor as aulas restantes em sua casa para os interessados. Dos 600 alunos matriculados, apenas 21 participantes continuaram a frequentar o curso em casa de Castilho, dentre eles, o representante da província alagoana. Nesse momento, deparamos com a necessidade de questionar: quem são esses 21 restantes, além do professor Francisco Soares? Que pareceres esses sujeitos levaram às suas provinciais, após a realização do curso?

O método Castilho não foi adotado na província goiana, embora o representante enviado tenha constatado melhor resultado em um mesmo espaço de tempo. Para além dos motivos nacionalistas citados por Costa (2011) da parte de professores incapazes de admitir mudanças, localizamos resistência ao método em virtude de retaliações pessoais de professores na província alagoana. Tratam-se de disputas por cadeira no liceu de Alagoas, motivadas politicamente, apresentadas inclusive nos jornais de Alagoas. 
Resistência e confronto, Castilho também recebera da parte do primeiro diretor da escola normal de Niterói, Costa e Azevedo, criador de um método de ensino no Brasil, fundado sob as bases do Ensino Universal de Jacotot. Costa e Azevedo era, nessa empreitada, acompanhado por seguidores como Valdetaro, professor da princesa Isabel e diretor da escola que levava o seu nome.

\title{
Construção e princípio do Ensino Universal de Joseph Jacotot
}

Jean Joseph Jacotot (1770-1840) nasceu em Dijon na França. É considerado um pedagogo francês. Estudou Direito em Dijon. Ensinou retórica e, depois, letras e matemática. Após a Revolução, foi oficial do exército francês, mas, após a queda de Napoleão, teve de se exilar na Bélgica. Em 1818, ainda exilado na Bélgica, aceitou um cargo na Universidade. Seus alunos não falavam francês e ele não falava flamengo. Após a Revolução de 1830, regressa à França na tentativa de propagar seu método de ensino, que buscava a emancipação intelectual através da educação. Perella (2011) aponta que os princípios e experiências pedagógicas de Jacotot foram propagados a partir da criação de uma sociedade pedagógica chamada Panécastique e de dois jornais: Journal de Philosophie Panécastique e Journal de l'Emancipation Intellectuel.

Segundo Albuquerque (2016), no Brasil tivemos a abertura do Instituto Panecástico baseado nas ideias de Jacotot. Na revista Sciencia (1848, v. 2, n. 16), publicada no Brasil, há uma explicação de seu Ensino Universal, da história de sua produção, bem como um resumo dos seus princípios e aplicação.

A Filosofia Panecástica de Jacotot encontrou seguidores no solo brasileiro, que, em 1847, a partir da vinda do francês Dr. Mure (1809-1858), criaram a Associação Panescática do Brasil para desenvolver os princípios do ensino universal de Jacotot.

\begin{abstract}
Aos três dias do mês de maio do ano de mil, oitocentos e quarenta e sete, em uma sala da casa da rua de São José, número cinquenta e nove, tendo-se reunido, a convite do Sr. Dr. De Mure, várias pessoas, o Dr. Mure propôs a fundação de uma sociedade para o desenvolvimento dos princípios de Jacotot sobre o ensino universal; aceita foi a proposta por unanimidade, e adotou-se o seguinte: em nome de Jacotot, inventor da filosofia panecástica, no dia 3 de maio de 1847. (SCIENCIA, 1847 , v.1, n. 3).
\end{abstract}

A proposta da Associação, fundada sob a base do pensamento de Jacotot, não se limitava ao campo da discussão. Foi aberto um fundo para a criação de escolas para aplicação do Ensino Universal de Jacotot:

Sob proposta do Sr. Dr. B. Mure, foi fundado o Instituto Panecástico do Brasil, cujos estatutos são os seguintes: o Instituto tem por fim propagar os princípios da emancipação intelectual do imortal Jacotot, e substituir à autoridade e ao pedantismo os direitos da razão humana. (SCIENCIA, 1847, v. 1, n. 3).

Os sócios reuniam-se em uma assembleia geral, convocada uma vez por ano, no dia do aniversário da morte de Jacotot e a instituição promovia conferências semanais para esclarecimentos sobre a aplicação do Ensino Universal. O periódico Sciencia (1847, v. 1, n. 5) reclamava do fato de as escolas primárias existentes não associarem o Ensino Universal de Jacotot ao método de ensino mútuo. É elogiada a introdução do método de ensino mútuo aliado ao ensino simultâneo. 
Como não sabia Flamengo, Jacotot deixava os alunos aprenderem por si; e se surpreendia positivamente com a constante superação dos discípulos, que, apesar de terem um 'mestre ignorante', conseguiam aprender.

Ele esperava um dilúvio de barbarismos, e até talvez uma absoluta impossibilidade de exprimirem-se. E, com efeito, como podiam esses moços, privados de explicações, reduzidos a si mesmos, compreender e resolver as dificuldades de uma língua inteiramente nova para eles? [...] Qual não foi a admiração do Sr. Jacotot ao descobrir que esses alunos, sem outro guia, sem outros recursos, que a sua reflexão individual, tinham desempenhado a sua árdua tarefa tão bem como o poderiam ter feito muitos franceses! As explicações então tornavam-se desnecessárias? Porventura bastaria querer para poder? (SCIENCIA, 1848, v. 2, n. 16).

Dessa experiência, começou-se a divulgar a ideia de que se pode ensinar aquilo que se desconhece.

Do sucesso que sempre tinha coroado as suas tentativas, concluiu o Sr. Jacotot 'que Deus criou a alma humana capaz de instruir-se a si mesma, e sem o concurso de mestres e explicadores'. Enunciou ainda o Sr. Jacotot outros princípios: 'aprender ou saber alguma coisa é a ela referir todo o resto. Tudo se acha em qualquer coisa. Todas as inteligências são iguais. Pode-se ensinar aquilo que se ignora'. Isso quer dizer, simplesmente, que que quiser, seja quem for, pode, tendo confiança em si e vontade, verificar se uma outra pessoa sabe o que tem aprendido". (SCIENCIA, 1848, v. 2, n. 16).

A definição do termo Panecástica advém desse princípio da igualdade dos seres falantes, fundamentado na máxima expressa em seu Ensino Universal que "tudo está em tudo". Rancière (2015) discorre sobre a filosofia Panecástica, termo esse batizado por Jacotot, a partir da junção de duas palavras gregas, "buscando o todo da inteligência humana em cada manifestação individual. (RANCIÈRE, 2015, p. 64).

$\mathrm{Na}$ defesa pela emancipação intelectual proposta pela Filosofia Panecástica e registrada no Ensino Universal de Jacotot, Rancière (2015) critica as discussões limitadas à forma de ensinar, ao Ensino Universal propriamente dito, que esvazia o discurso de suas condições materiais e políticas e não problematiza o princípio da desigualdade de condições entre os homens, levando-os a um embrutecimento.

O velho não embrutece seus alunos ao fazê-los soletrar, mas ao deizer-lhes que não podem soletrar sozinhos; portanto, ele não os emanciparia, ao fazê-los ler palavras inteiras, porque teria todo o cuidado em dizer-lhe que sua jovem inteligência não pode dispensar as explicações que ele retira do seu velho cérebro. Não é, pois, o procedimento, a marcha, a maneira que emancipa ou embrutece, e o princípio. (RANCIÈRE, 2015, p. 50).

Em um olhar de longa duração, pode-se contrastar discussões advindas das diferentes matrizes teóricas que circulavam no Império Brasileiro, como o princípio educativo do Ensino Universal, proposto por Jacotot, que parte de uma tomada de posição diferente do mestre, menos preocupado em transmitir conhecimentos e em buscar métodos de ensino, e mais com a emancipação intelectual do seu aluno, a partir do pressuposto da igualdade das inteligências.

Ao criticar métodos que se valiam dos meios escolhidos para tornar sábio o ignorante, sem, entretanto, partir da concepção de igualdade intelectual entre todos os 
homens, o autor considera que se distinguem apenas os "meios escolhidos para tornar sábio o ignorante: métodos duros ou suaves, tradicionais ou modernos, passivos ou ativos, mas cujo rendimento se pode comparar". (RANCIÈRE, 2015, p. 32). Nesses métodos, o aproveitamento escolar da criança é construído a partir de uma visão de infância passiva, civilizada e embrutecida.

A crítica de Jacotot dirigia-se, portanto, aos métodos que circulavam em sua época, e que se reportavam a uma escola disciplinadora, modeladora, normalizadora e reguladora da cultura letrada. Observa-se em Jacotot uma visão problematizadora, descrita por Rancière na forma de perguntas: "a criança está compreendendo? Ela não compreende? Encontrarei maneiras novas de explicar-lhe, mais rigorosas em seu princípio, mais atrativas em suas formas; e verificarei que ele compreendeu". (RANCIÈRE, 2015, p. 24).

O mestre Jacotot colocava-se na posição de mestre ignorante, como forma de romper com o que ele acreditava ser o embrutecimento de seus alunos. Nesse sentido, havia sim pontos de convergência com a perspectiva de Castilho.

Essa breve incursão pela circulação do Ensino Universal de Jacotot no Brasil visa apenas compará-lo com o método Castilho, para em seguida dar sequência à análise. Se, em Castilho, há uma crítica sobre o método que ensina a "ler por sílabas, somando-as como elementos à palavra; bestice inclassificável e imperdoável" (CASTELO-BRANCO, 1977), observa-se que a preocupação de Jacotot direciona-se a outros rumos, a uma epistemologia do conhecimento, que problematiza o princípio da desigualdade da condição dos homens na aplicação de métodos que levam a um "embrutecimento". Dessa forma, para Jacotot, o que emancipa ou embrutece não é o procedimento, a marcha, o método; e sim o princípio. Em defesa do princípio da igualdade de todos perante o aprendizado, no seu ensino esse é o ponto de partida, que deve ser mantido em qualquer circunstância...

\section{A rejeição do Método Castilho no Brasil: o confronto com adeptos do Método Jacotot}

Castelo-Branco (1977) descreve o conteúdo das cartas ${ }^{2}$ enviadas por Castilho à sua mulher, quando de sua estadia no Brasil, para a ministração do curso. Uma minuciosa análise dessa correspondência pedagógica foi imprescindível na busca por respostas aos diversos questionamentos levantados durante esta pesquisa. Nessa correspondência, analisada sob a descrição de Castelo-Branco (1977), Castilho escreve estar desanimado em relação aos frequentadores de seu curso no Brasil. Diz que são todos nacionalistas que recusam qualquer experimentação, dizendo-se adeptos de um método exclusivamente brasileiro, calcado nas orientações de Jacotot:

Quanto ao curso, creio que não posso dizer outro tanto, foi muito frequentado, mas nada mais. Esta gente é indolentíssima e tem ainda uma qualidade pior, ou que pelo menos foi pior para o nosso caso: leva o seu patriotismo a um ponto de fúria que faz rir. Como o método é português e eles têm aqui um chamado Costa Azevedo, que fez uma redução e estropiação de Jacotot, impresso há vinte e um anos, mas desconhecido, pode-se dizer que, por toda a gente, se aproveitaram da franqueza com que sempre convido a discutir e a objetar, para virem pôr seus reparos, sob

\footnotetext{
2 Esse estudo baseia-se na Correspondência Pedagógica de A. F. de Castilho, seleção, introdução de notas de Fernando Castelo-Branco, publicada em 1975, pelo Centro de Investigação Pedagógica da Fundação Calouste Gulbenkian e nas Memórias de Castilho, escritas por seu filho Júlio de Castilho. Uma parte dessa obra está publicada em livro, mas a outra apenas foi divulgada na revista $O$ Instituto de Coimbra.
} 
formas muito corteses na verdade, mas completamente sofísticas e de péssima fé. (CASTELO-BRANCO, 1977, p. 285).

Nas falas de Castilho, observa-se que o Brasil já possuía, desde 1834, um método de leitura, fruto de apropriação do sistema pedagógico francês de Jacotot, organizado pelo brasileiro Costa Azevedo, que era o pomo da discórdia, das intrigas e sobretudo da rejeição brasileira ao método Castilho.

\begin{abstract}
Dois traquinas literários com muita bazófia, num discurso muito sobrecarregado de encômios a mim, como escritor e poeta, e muito revestidos de fórmulas hipócritas, procuraram suscitar (e, com efeito, suscitaram) uma cizânia de nacionalidade chocha, dizendo que também havia aqui, impresso há vinte e um anos, um método de leitura, coisa grande, feito por um grande homem, em quem a maior parte deles mesmos nunca ouvira falar, chamado José da Costa e Azevedo; que decerto não teria tirado dele o meu, mas que me havia com ele encontrado; que, por aquele método, se aprendia em seis meses como se podia ver num colégio desta cidade, etc., etc., etc. (CASTILHO apud CASTELO-BRANCO, 1977, p. 286).
\end{abstract}

Castilho descreve sua visão sobre o autor do método brasileiro João da Costa e Azevedo e seu seguidor, Francisco Crispiniano Valdetaro. Este último foi professor da princesa Isabel Cristina, filha do imperador D. Pedro II. Segundo seu biógrafo, ele nasceu em 1805 e faleceu em 1862 (CALMON, 1941). Tanto Costa e Azevedo quanto Valdetaro estiveram dentre os 600 sujeitos que participaram do curso de Castilho no Brasil, fazendo Castilho "perder a cabeça em duas lições".

O [método] de seu plagiário Costa, ninguém o segue no Império, não o conhecem aqueles mesmos que falam dele; e o tal colégio que se apontava, e que pertence a um Fulano Valdetaro, ensina por uma modificação feita pelo mesmo Valdetaro ao mesmo Costa, mas leva-nos para dar maus ledores. Esses dois oradores de tão insigne tarefa fizeram-me perder a cabeça em duas lições. Afinal já levavam para lá clientes, para Ihes darem apoiados; era insuportável. Trunquei ali o curso, dizendoIhe o porquê muito francamente. (CASTILHO apud CASTELO BRANCO, 1977, p. 286).

Na primeira biografia da herdeira do trono do Brasil, a obra de Calmon (1941), trata em seu terceiro capítulo sobre a educação da princesa Isabel, apontando para a presença do professor Dr. Francisco Valdetaro e da utilização do método do professor José da Costa e Azevedo.

A filha aproveitou-lhe mais a lição do que o pai, cuja péssima letra se tornava por vezes ilegível. Os estudos gerais da menina aos 11 anos estavam a cargo do Dr. Francisco Crispiniano Valdetaro. Era um pedagogo sério que tinha Colégio disciplinado pelo método do professor José da Costa e Azevedo. (CALMON, 1941, p. 19).

No cruzamento dessas fontes, deparamo-nos com o desabafo de Castilho frente à presença de professores com grande prestígio em solo brasileiro, a cargo da instrução da princesa, fato esse que deixa grandes questionamentos: será que a princesa teria a cargo de sua instrução um professor "possuidor de uma escola de maus ledores", como Castilho descrevera Valdetaro? Será que o método apropriado de Jacotot era mesmo desconhecido até por quem o praticava, conforme as falas de Castilho? Tais são as indagações que justificam a necessidade dessa investigação no território da historiografia da educação brasileira. 


\section{Considerações finais}

Entre as idas e vindas do português Antonio Feliciano de Castilho no campo dos métodos de ensino da leitura, tanto em Portugal como no Brasil, deparamo-nos com embates, resistências, negações, em um espaço, denominado pelo próprio autor, como repleto de opositores.

Nesse escrito, foram contempladas as rejeições que Castilho recebera em território brasileiro sob a lente, principalmente, de três localidades distintas: as províncias de Goiás e de Alagoas, e ainda uma remissão à Corte Imperial, onde seu curso fora cancelado. As fontes localizadas demonstram as dificuldades que o Método Castilho recebeu por vislumbrar uma escola moderna, calcada em princípios da simultaneidade do ensino, de uma escola ativa, alegre e que despertasse $o$ interesse das crianças.

Castilho desdenhou da escola que não nascera da sua pena, não se intimidando aos ataques recebidos, defendendo-se em diferentes registros em forma de respostas aos que considerou, seus adversários e impugnadores.

Em solo brasileiro, os impasses e recusas ao Método Castilho deveram-se a motivos pessoais, como os embates com o filólogo alagoano José Alexandre Passos; ainda pela oposição que sua metodologia de ensino baseado na atividade lúdica e alegria para o aluno, recebera por não preparar para as "durezas da vida", e ainda pela presença de autores no campo do ensino da leitura como o brasileiro Costa e Azevedo. Em tom de denúncia, Castilho registrou em carta a sua mulher que os nacionalistas brasileiros, especialmente Costa e Azevedo e Valdetaro, rejeitaram seu método e sua presença na Corte devido à inflamação que tais nacionalistas incitaram em suas aulas.

$\mathrm{Na}$ continuação de seus registros à sua esposa, Castilho acusou o brasileiro Costa e Azevedo de plagiário de Joseph Jacotot. Em um contexto de internacionalização de ideias pedagógicas, deparamos com embates no campo da instrução pública primária em solo brasileiro, envolvendo as matrizes portuguesa e francesa.

Se o português Castilho vislumbrava uma escola seriada, ritmada, com ensino simultâneo, arquitetonicamente projetada e regida por um professor, para o francês Jacotot, a destruição de toda essa estrutura e a presença de um mestre ignorante, porém emancipado e com a capacidade de emancipar seu aluno, salvaria o processo educativo de todos os métodos embrutecedores desenvolvidos em seu tempo histórico.

Jacotot criticava as preocupações com os métodos que alteravam os "[...] meios escolhidos para tornar sábio o ignorante, métodos duros ou suaves, tradicionais ou modernos, passivos ou ativos, mas cujo rendimento se podia comparar; sem entretanto, partir da concepção de igualdade intelectual entre todos os homens [...]" (RANCIÈRE, 2015, p. 32). Sua crítica dirigia-se ao rendimento mensurável, à essa escola racionalizada em todos os seus tempos e espaços, permeada pela concepção de uma criança passiva, civilizada e, em suas palavras, embrutecida.

Dessa forma, pode-se inferir, que suas críticas lançadas aos métodos embrutecedores envolviam o de Castilho pois, apesar de buscar trazer um caminho mais suave, mais ativo, este fundamentava-se no trabalho regido pelo regente da orquestra escolar: o professor. A crítica silenciada de Jacotot dirigia-se aos métodos que atendiam à proposta da escola moderna, caracterizada em suas funções disciplinadora, modeladora, normatizadora e reguladora da cultura letrada. 
O princípio essencialista de sua Filosofia Panecástica expresso em seu Método Universal, sob a máxima que "tudo está em tudo" criticava a inculcação de fórmulas, e das partes, em detrimento de uma pedagogia experimentalista, que contemplasse o todo de cada manifestação. Essa era a máxima da Panecástica, termo esse batizado por Jacotot, a partir da junção de duas palavras gregas, "buscando o todo da inteligência humana em cada manifestação individual. (RANCIÈRE, 2015, p. 64).

Finalmente, à luz do estudo sobre a vida e obra de Antonio Feliciano de Castilho, foram apresentados sujeitos, ideais e impressos no campo da instrução pública primária no Império brasileiro, demarcando inúmeras presenças em um contexto histórico marcado por tantas ausências. Se iniciamos a escrita apontando para as carências que a escola imperial brasileira recebeu ao longo da historiografia da educação, registramos, neste escrito, um campo repleto de articulações, estudos, matrizes, ideias, impressos, debates, rupturas, apropriações, resistências, em um olhar historiográfico para além das carências e silêncios...

\section{Referências}

A SCIENCIA. Disponível em: <http://memoria.bn.br/DocReader/docreader.aspx?bib= 730076\&pesq>. Acesso em: 10 mar. 2016.

ABREU, Sandra Elaine Aires de. A instrução primária na província de Goiás no século XIX. 2006. Tese (Doutorado) - Pontifícia Universidade Católica de São Paulo/PUC-SP, São Paulo, 2006.

Tempos e espaços escolares nas escolas de primeiras letras da província de Goiás no século XIX. Revista Educação \& Mudança, v. 20/21, p. 90-106, 2008.

ALBUQUERQUE, Luís. Notas para a história do ensino em Portugal. Coimbra: Textos Vértice, 1960.

ALBUQUERQUE, Suzana Lopes de. Análise de impressos no Brasil Império: o periódico A Sciencia e sua interlocução com o campo pedagógico. In: CONGRESSO INTERNACIONAL DE HISTÓRIA, V, 2016. Universidade Federal de Goiás, Jataí. Anais... UFG: Jataí, 2016.

O ensino de primeiras letras de Alagoas oitocentista: vestígios sobre noções de infância nos discursos e práticas escolares. 2013. 157 f. Dissertação (Mestrado em Educação) - Programa de Pós-graduação em Educação, Universidade Federal de Alagoas, 2012.

ARAÚJO, Joaquim José de. Compendio de pedagogia prática - para uso na Escola Normal de Maceió. Salvador: Tipografia dos Dois Mundos, 1886.

BATISTA, Antônio Augusto Gomes. O conceito do livro didático. In: BATISTA, Antônio Augusto Gomes; GALVÃO, Ana Maria De Oliveira. Livros escolares de leitura no Brasil: elementos para uma história. Campinas, SP: Mercado de Letras, 2009. p. 41-74.

BOTO, Carlota. A escola primária como rito de passagem: Ler, escrever, contar e se comportar. Coimbra: Imprensa da Universidade de Coimbra, 2012.

. Castilho e João de Deus: rastros do ensino da leitura e da escrita em Portugal do século XIX. In: CASTELLANOS, Samuel Luis Velázquez; CASTRO, Cesar Augusto. Livro, leitura e leitor: perspectiva histórica. São Luís: Café \& Lápis/Edufma, 2016. p. 265-285.

BRASIL. Collecção das leis do Imperio do Brasil. Decreto no 1331a - de 17 de 
Fevereiro de 1854.

. Constituição de 1824.

Brasil-Portugal: revista quinzenal ilustrada. Lisboa, v. I, n. 25, p. 109, fev. 1900.

CALMON, Pedro. A princesa Isabel - a redentorna. Biblioteca pedagógica brasileira.

Companhia Editora Nacional: São Paulo/Rio de Janeiro/Recife/Porto Alegre, 1941.

CASTELO BRANCO, Fernando. Castilho tenta difundir o seu método de leitura no

Brasil. Revista da Faculdade de Educação, USP, 3 (1), p. 32-45, jun. 77.

. Introdução. In: CASTILHO, Antonio Feliciano. Correspondência pedagógica.

Lisboa: Instituto Gulbenkian de Ciência, Centro de Investigação Pedagógica, 1975. p. 731.

CASTILHO, Antonio Feliciano. Ajuste de contas com os adversários do methodo portuguez. Lisboa: Empreza da História de Portugal Sociedade Editora, Livraria Moderna Typographia, 1909e.

Camões: estudo histórico poético liberrimamente fundado sobre um drama francez dos snrs. Victor Perrot e Armand Dumesnil. 3. ed. portugueza. V. II. Lisboa: Empreza da História de Portugal Sociedade Editora, Livraria Moderna Typographia, 1906.

Correspondencia pedagógica: selecção, introdução e notas de Fernando Castelo-Branco. Lisboa: Instituto Gulbenkian de Ciência, Centro de Investigação Pedagógica, 1975.

Discurso preliminar da quarta edição do Methodo Portuguez Castilho offerecido pelo autor á consideração de todas as pessoas illustradas, patrioticas e influentes. Lisboa: Typ. do Progresso, 1857.

Felicidade pela agricultura. 2. ed. v. II. Lisboa: Empreza da História de Portugal Sociedade Editora, Livraria Moderna Typographia, s/d.

Felicidade pela instrucção. 3. ed. Lisboa: Empreza da História de Portugal Sociedade Editora, Livraria Moderna Typographia, 1909a.

Método Castilho para o ensino rapido e aprasivel do ler impresso, manuscrito, e numeração e do escrever, 1880. Disponível em:

$<$ http://sigarra.up.pt/up/web_base.gera_pagina?p_pagina=1001565>. Acesso em: 20 dez 2012.

Os cumes do bardo. Lisboa: Empreza da História de Portugal Sociedade Editora, Livraria Moderna Typographia, 1907c.

Ou eu ou eles: tosquisa de um camello - carta a todos os mestres das aldeias e das cidades. Lisboa: Empreza da História de Portugal Sociedade Editora, Livraria Moderna Typographia, 1910.

Resposta aos novíssimos impugnadores do Methodo Portuguez. v. I. Lisboa: Empreza da História de Portugal Sociedade Editora, Livraria Moderna Typographia, 1909b.

Resposta aos novíssimos impugnadores do Methodo Portuguez. v. II. Lisboa: Empreza da História de Portugal Sociedade Editora, Livraria Moderna Typographia, 1909c.

Resposta aos novíssimos impugnadores do Methodo Portuguez. v. III. Lisboa: Empreza da História de Portugal Sociedade Editora, Livraria Moderna Typographia, 1909d. 
Telas literárias. v. II. Lisboa: Empreza da História de Portugal Sociedade Editora, Livraria Moderna Typographia, 1907a.

Telas literárias. v. IV. Lisboa: Empreza da História de Portugal Sociedade Editora, Livraria Moderna Typographia, 1907b.

CATROGA, Fernando. Os caminhos polémicos da 'geração nova'. In: MATTOSO, José (Dir.). História de Portugal. Quinto volume. Lisboa: Círculo de Leitores, 1993. p. 569-581. CHOPPIN, Alain. O historiador e o livro escolar. História da Educação, n. 11, p. 5-24, abr. 2002.

COMENIUS, Jan Amos. A escola da infância. Tradução: Wojciech Andrzej Kulesza. São Paulo: Ed. Unesp, 2011.

CORREIA, Rita. Brasil-Portugal. Texto disponibilizado no site da Câmara Municipal de Lisboa. Disponível em <http://sigarra.up.pt/up/web_base_gera_pagina>. Acesso em: 20 fev. 2016.

COSTA,_João Craveiro. Instrução Pública e Instituições Culturais em Alagoas. Maceió: Edufal, 2011.

CRUZ, Crislaine Santana; BRETAS, Silvana Aparecida. O método da igualdade: Jacotot e a experiência do ensino universal no contexto da Revolução Francesa. In: REUNIÃO ANUAL DA ANPED, 38ª, out. 2017. UFMA, São Luís/MA. Anais... São Luís/MA: UFMA, p. $1-17$.

D’AÇA, Zacharias. Memórias literárias: Antonio Feliciano de Castilho. Brasil-Portugal: revista quinzenal ilustrada, Lisboa, v. I, n. 25, p. 109, fev. 1900.

DALIGAULT. Curso pratico de pedagogia: destinado aos alunos das escolas normaes primarias, aspirantes ao magistério e aos professores em exercício. Tradução de Frano de Pauliscéa Marques de Carvalho. Santa Catarina: Typografia de Ribeiro \& Caminha, 1870.

DUARTE, Abelardo. História do Liceu alagoano. Maceió: Divulgação do Departamento Estadual de Cultura, 1961.

FERREIRA, Alberto; MARINHO, Maria José. Antologia de textos da 'Questão Coimbrã'. Lisboa: Moraes Editores, 1980.

GALLEGO, Rita de Cassia. O que e como ensinar? A arquitetura de tempos, ritmos e rituais de ensinar e aprender nas escolas primárias paulistas (1846-1890). In: CATANI, Denice Barbara; GATTI JR., Décio. 0 que a escola faz? Elementos para a compreensão da vida escolar. Uberlândia: Edufu, 2015. p. 251-289.

GALHARDO, José Emygdio Rodrigues. História da homeopatia no Brasil. In: Livro do ${ }^{\circ}$ Congresso Brasileiro de Homeopatia. Rio de Janeiro, 1928. (BN)

GOIÁS, Relatório do presidente da província de, Antonio Candido da Cruz Machado. 1855. Apresentado á Assemblea Legislativa de Goyaz na Sessaõ Ordinária de 1855. Typographia Provincial de Goyaz. Sociedade Goiana de Cultura. Instituto de Pesquisas e Estudos Históricos do Brasil Central. Centro de Cultura Goiana. Relatórios dos governos da Província de Goyaz de 1854-1856: relatórios políticos, administrativos, econômicos, religiosos etc. Goiânia: Ed. da UCG, 1997. (Memórias Goianas, 6).

MORTATTI, Maria do Rosário Longo. Os sentidos da alfabetização. São Paulo: Editora Unesp, 2000.

OLIVEIRA, Cátia Regina Guidio Alves. Alfabetização em Portugal no século XIX. In: GOBBI, Márcia Zamboni; JUNQUEIRA, Renata Soares. Literatura e história: Portugal 
em foco. Centro de Estudos Portugueses “Jorge de Sena”: FCL/Unesp-Araraquara, 1997. p. 205-219.

. João de Deus, a Cartilha Maternal e o ensino da leitura em Portugal. História da

Educação, Asphe/FaE/UFPel, n. 4, set. 1998. Pelotas: Editora da UFPel, p. 49-56.

PERELLA, Cileda dos Santos Sant'Anna. Joseph Jacotot: contribuição para a reflexão acerca do conselho de escola. In: SIMPÓSIO BRASILEIRO DE POLITICA E ADMINISTRAÇÃO DA EDUCAÇÃO, 25 / CONGRESSO IBERO-AMERICANO DE POLÍTICA E ADMINISTRAÇÃO DA EDUCAÇÃO, 2ํㅡㄴ, Associação Nacional de Política e Administração da Educação - ANPAE, 2011. São Paulo. Anais... São Paulo: ANPAE, 2011. p. 1-15.

RANCIÈRE, Jacques. O mestre ignorante: cinco lições sobre a emancipação intelectual. Tradução de Lílian do Valle. 3. ed. 4. reimp. Belo Horizonte: Autêntica Editora, 2015.

SARAIVA, António José; LOPES, Óscar. História da literatura portuguesa. 16. ed. Porto: Porto Editora, s/d.

SIMÕES, João Gaspar. A Geração de 70. 2. ed. Lisboa: Editorial Inquérito, s/d.

CARLOTA BOTO é professora na Faculdade de Educação da Universidade de São Paulo (USP). É autora dos livros A liturgia escolar na Idade Moderna, publicado pela Editora Papirus e Instrução pública e projeto civilizador, publicado pela Editora Unesp. É bolsista produtividade 1D do CNPq.

Endereço: Alameda Franca, 260 - ap. 102, 01422-000, São Paulo/SP, Brasil

E-mail: reisboto@usp.br

SUZANA LOPES DE ALBUQUERQUE é professora do Instituto Federal de Educação de Goiás, Câmpus Goiânia Oeste, doutoranda no programa de Educação na Universidade de São Paulo (USP) e bolsista Piqs - IFG. É líder do Grupo de pesquisa Panecástica.

Endereço: Rua Augusto Gontijo, qd. 43, It. 13, n. 129, Cidade Jardim, 74423-440, Goiânia/GO, Brasil.

E-mail: suialopes@hotmail.com

Recebido em 31 de outubro de 2017.

Aceito em 21 de fevereiro de 2018. 